\title{
FATIGUE RESISTANCE OF C30 STRUCTURAL STEEL
}

In this paper the authors present and discuss results of both fatigue life tests and fatigue crack growth rate tests performed for C30 steel which is used for railway axle manufacturing. The obtained results demonstrate the differences in fatigue strength and fatigue crack growth resistance in two different parts of one railway axle which are subjected to different levels of plastic deformation, namely the axle bolster body and axle body.

Keywords: Fatigue strength, crack growth resistance, C30 steel, railway axle.

\section{Introduction}

In spite of years of intensive research, fatigue of metals is still a serious engineering problem and fatigue fractures appear very frequently on common cyclically loaded structural components [1 and 2]. With respect to the technology used for manufacturing, different microstructural and work hardening states can be present in just one structural component. This means that different parts of the component can have different fatigue properties and tests done using specimens prepared from various parts are not equal [3 and 4].

Various tests can be performed to evaluate fatigue properties of materials. Most commonly used are standard fatigue life tests in which the specimen is cyclically loaded until it fractures and fatigue crack growth tests where the resistance of material to fatigue crack growth is evaluated. Even when both tests refer to fatigue resistance, each of them provides information about different material characteristics. Standard fatigue life tests provide information about number of cycles which are necessary for fatigue crack initiation and propagation through the whole cross section until complete fracture occurs. However, fatigue crack growth tests provide information about the resistance of the material microstructure to fatigue crack propagation. This means that correct interpretation of these test results is extremely important because they can provide even completely opposite results [2, 5 and 6$]$.

The fatigue life and fatigue crack growth resistance of specimens prepared from different parts of a railway axle manufactured from C30 structural steel are analysed in this study. Results are discussed in the light of the ratio between the number of cycles necessary for fatigue crack initiation and propagation and the ability of a material with lower strength to create a plastically deformed zone on the crack tip which slows down further fatigue crack propagation.

\section{Material and methods}

C30 steel obtained from a manufactured railway axle was used as experimental material. Quantitative chemical analysis (Table 1) confirmed that the chemical composition meets the standard prescribed for this steel [7 and 8].

C30 steel chemical composition in weight $\%$

Table 1

\begin{tabular}{|c|c|c|c|c|c|c|c|c|}
\hline $\mathbf{C}$ & $\mathbf{M n}$ & $\mathbf{S i}$ & $\mathbf{P}$ & $\mathbf{S}$ & $\mathbf{C u}$ & $\mathbf{N i}$ & $\mathbf{C r}$ & $\mathbf{A l}$ \\
\hline 0.26 & 0.96 & 0.35 & 0.019 & 0.02 & 0.05 & 0.02 & 0.07 & 0.017 \\
\hline
\end{tabular}

To produce a railway axle large steel ingots are used. They are hot-rolled to a bar-shaped semi-product. After hot-rolling, homogenisation annealing and normalising are carried out with the aim to homogenise the chemical composition and polyhedrisation of the deformed material grains. The microstructure is then formed by polyhedral ferritic and pearlitic grains [ 8 and 9]. This bar is then die forged to a shape very close to the final axle and machined for a final axle. The resulting mechanical properties are determined by the degree of plastic deformation during the die forging process. To assure high value of plastic deformation strengthening, large degree of area reduction during the die forging process is necessary and the hot rolled bar diameter must be at least double the size of the largest diameter of the final axle.

\footnotetext{
* ${ }^{1}$ Libor Trsko, ${ }^{1,2}$ Otakar Bokuvka, ${ }^{2}$ Peter Palcek, ${ }^{1,2}$ Frantisek Novy, ${ }^{1}$ Katarina Mikova

${ }^{1}$ Research Centre of University of Zilina, Slovakia

${ }^{2}$ Faculty of Mechanical Engineering, University of Zilina, Slovakia

E-mail: libor.trsko@rc.uniza.sk
} 


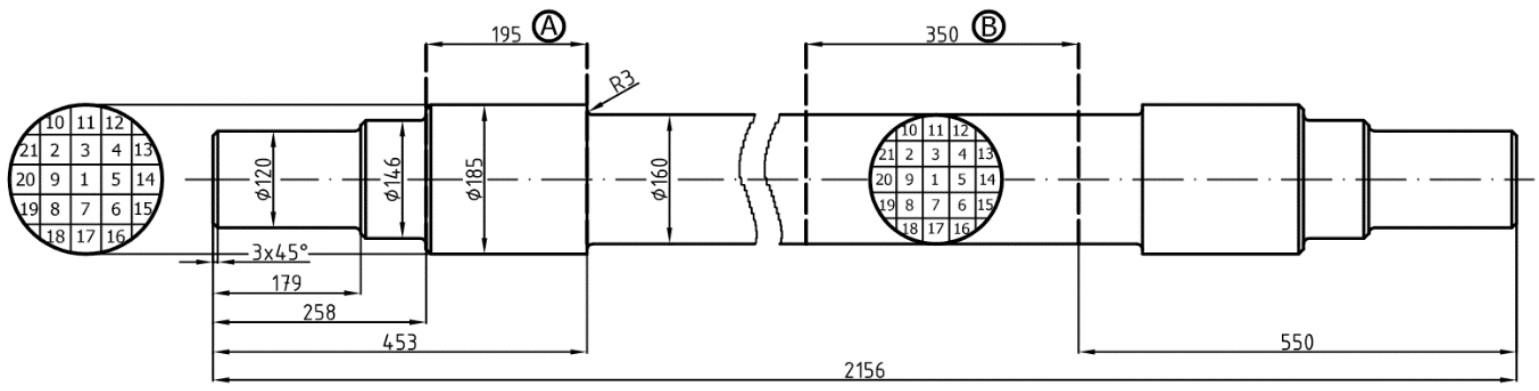

Fig. 1 Drawing of the tested railway axle and sketch of machining position of the specimens

Deformation strengthening by die forging is more significant on the surface than in the core of the material. However, during machining process a part of the strengthened surface layer is removed. The depth of removed layer is higher in the body of axle (the middle part of the axle with diameter of $160 \mathrm{~mm}$ in Fig. 1 , marked B) than in the axle bolster (the part of the axle with diameter of $185 \mathrm{~mm}$, marked A in Fig. 1).

Removing of the surface layer also causes compressive residual stress relief from the material. The stress relief is again more significant when a deeper surface layer of material is machined of. Due to these facts, the mechanical properties of various parts of the axle can differ. Tensile test specimens and fatigue test specimens were machined from a new, not used railway axle (Fig. 1). One set was machined from the axle bolster (marked A in Fig. 1) and another from the axle body (marked B in Fig. 1). The position of the machined specimen, with respect to the cross section position, is described by the drawn mesh in the circles representing the cross sections (Fig. 1).

Specimens for ultrasonic fatigue tests (Fig. 2a) were machined from all 21 bars. Each specimen's gauge length was ground and polished by diamond metallographic emulsion. To obtain the mathematical dependence of the number of cycles to failure on the loading stress amplitudes, experimental results were approximated by the Basquin function, using the least square method [9]:

$$
\sigma_{a}=\sigma_{f}^{\prime}\left(N_{f}\right)^{b}
$$

in which $b$ is the exponent of fatigue life curve and $\sigma_{f}^{\prime}$ is the coefficient of fatigue toughness obtained by the extrapolation of stress amplitude on the first loading cycle.

Fatigue crack growth was measured using the specimens according to Fig. 2b, also with polished surface of the gauge length. Primary notch with $1 \mathrm{~mm}$ in diameter and depth of $0.8 \mathrm{~mm}$ was manufactured by drilling and served as initiator for the fatigue crack. From the rest of bars from positions marked 1, 3 and 11 specimens for tensile tests were machined (Fig. 2c.). Fatigue tests were performed in the high and ultra-high cycle region by ultrasonic tension-compression loading ( $\mathrm{f}=20 \mathrm{kHz}, \mathrm{R}=-1, \mathrm{~T}=$ $20 \pm 3{ }^{\circ} \mathrm{C}$ ) [2, 10 and 11]. Fatigue crack growth measurement was performed using rotating-bending loading $(f=40 \mathrm{~Hz}, \mathrm{R}=-1$,

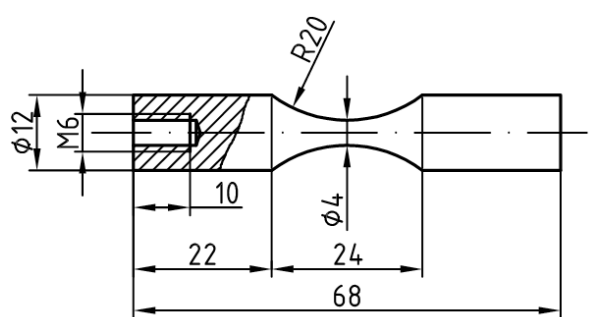

(a)

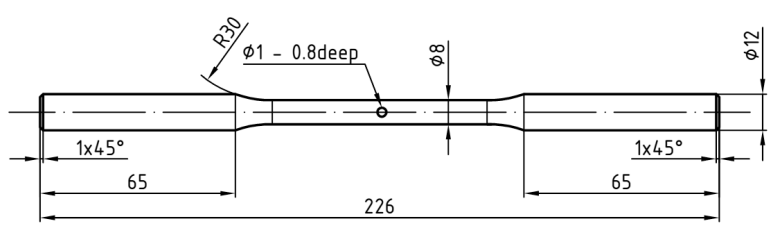

(b)

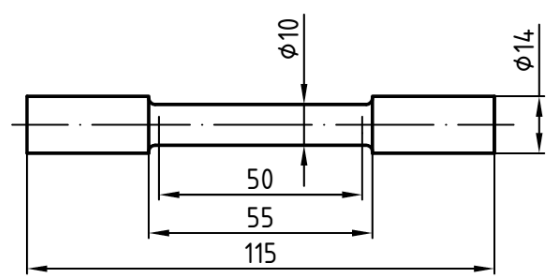

(c)

Fig. 2 Geometry of specimens used for ultrasonic fatigue tests (a), fatigue crack growth tests (b) and tensile tests (c)

$\mathrm{T}=20 \pm 3{ }^{\circ} \mathrm{C}$ ) on the testing equipment ROTOFLEX-UBM [9]. The specimens for fatigue crack growth (Fig. 2b) were loaded with cyclic bending stresses $R_{0}=220 \mathrm{MPa}$ and $\mathrm{R}_{\mathrm{o}}=240 \mathrm{MPa}\left(\mathrm{R}_{\mathrm{o}} / \mathrm{R}_{\mathrm{m}}\right.$ $=0.38$ and 0.41 , place A; 0.39 and 0.42 , place $B$ ). The length of the fatigue crack which was growing from the primary notch was regularly measured on the specimen's circumference after each $\mathrm{N}=10^{4}$ cycles with accuracy of $0.1 \mathrm{~mm}$ by a Brinell - Epignost optical microscope. $2 a=f(N)$ dependencies were obtained from which fatigue crack growth rates $\mathrm{d} 2 \mathrm{a} / \mathrm{dN}$ vs. stress intensity factor range $\Delta \mathrm{K}$ dependencies $((\mathrm{d} 2 \mathrm{a} / \mathrm{dN}=\mathrm{f}(\Delta \mathrm{K}))$ were evaluated. The applied stress intensity factor range $\Delta \mathrm{K}$ was determined using the following equation [12]: 


$$
\Delta K=1.03 \times \frac{2}{\pi} \times R_{O} \times(\pi \times a)^{\frac{1}{2}}\left(\mathrm{MPa}^{1 / 2}\right)
$$

in which $R_{o}$ is bending stress (MPa), $a$ is the half crack length including primary notch $(\mathrm{m})$.

\section{Experimental results}

Tensile test results (as average values from the three tested specimens) are shown in Table 2. According to the results there is only a minor difference in the UTS of the specimens manufactured from different parts of the railway axle and the yield point is almost exactly the same. This means that when static loading is applied, there is no significant difference in the material properties of different axle parts.

The authors [9] determined by indirect ultrasonic resonance method [10] the modulus of elasticity of the specimen machined from position No. 14 (Fig. 1). For axle bolster (A) the value was $E=2.06506 \times 10^{11} \mathrm{~Pa}$ and for axle body (B) $E=2.05168 \times 10^{11} \mathrm{~Pa}$. This means that there is also no significant difference in the values of modulus of elasticity, which describes the response of material to loading in the area of elastic deformation.

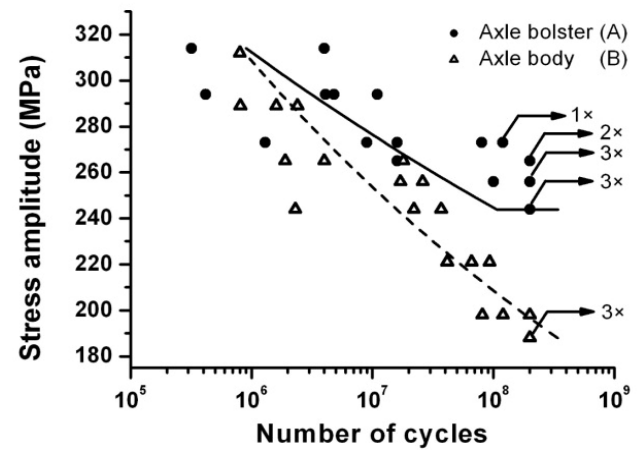

Fig. 3 Comparison of fatigue life of specimens machined from axle bolster and axle body, steel C30, tension-compression ultrasonic loading

$$
\left(f=20 \mathrm{kHz}, \mathrm{R}=-1, \mathrm{~T}=20 \pm 3{ }^{\circ} \mathrm{C}\right)
$$

According to the results of fatigue tests (Fig. 3), the fatigue strength of specimens machined from the axle bolster is higher than that of the specimens machined from the axle body. Specimens fracture was observed even beyond the conventional fatigue limit, usually evaluated for $\mathrm{N}=10^{7}$ cycles and the fatigue limit was estimated for $\mathrm{N}=2 \times 10^{8}$ cycles where the fatigue test was terminated and marked as run-out. Specimens were machined from the whole cross section of the axle parts which had different levels of deformation. This probably caused the high scatter of the results, but in general, the higher level of deformation in the axle bolster resulted in the fatigue limit (for $\mathrm{N}=2 \times 10^{8}$ cycles) $\sigma_{\mathrm{a}}=244 \mathrm{MPa}$ which is significantly higher than for the axle body where the fatigue limit was $\sigma_{\mathrm{a}}=188 \mathrm{MPa}$.

Results of fatigue crack growth tests (Fig. 4), the dependence of fatigue crack growth rates vs. stress intensity factor range, show that material from the axle body has a higher resistance to the fatigue crack growth than material in the axle bolster. Again the high scatter of results is probably caused by different deformation levels of material from the surface and from the core of the railway axle.

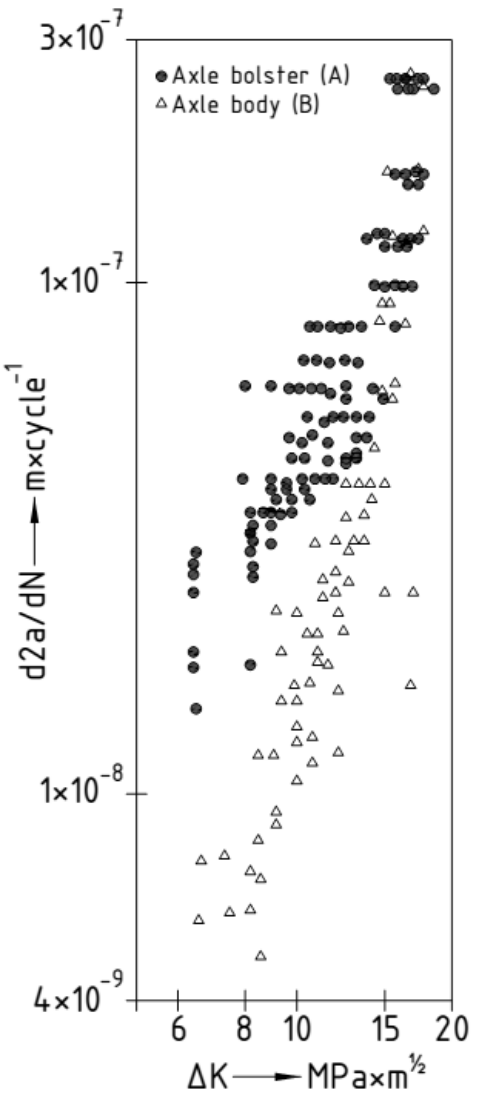

Fig. 4 Fatigue crack growth rate, steel C30, rotating-bending loading $\left(f=40 \mathrm{~Hz}, R=-1, T=20 \pm 3{ }^{\circ} \mathrm{C}\right.$ )

Results of tensile tests of steel C30

Table 2

\begin{tabular}{|c|c|c|c|c|c|}
\hline \multicolumn{3}{|c|}{ Axle bolster (A) } & \multicolumn{3}{c|}{ Axle body (B) } \\
\hline Yield point (MPa) & UTS (MPa) & Elongation (\%) & Yield point (MPa) & UTS (MPa) & Elongation (\%) \\
\hline 335.2 & 572.9 & 29.5 & 338.1 & 559.1 & 30.6 \\
\hline
\end{tabular}




\section{Discussion}

Due to different deformation levels of various parts of just one structural component caused by the manufacturing process, the fatigue properties of these parts can significantly differ. This was confirmed by ultrasonic fatigue tests in the high and ultrahigh cycle region where the fatigue limit of material in the area of axle bolster was higher than that of the material in axle body; the difference being $\Delta \sigma_{\mathrm{a}}=56 \mathrm{MPa}$. This significant difference in fatigue properties, although expected on the basis of information about the manufacturing process, is neither reflected in the results of standard tensile test, nor in the value of ultimate tensile strength, nor in the value of yield point [11 and 13].

The fatigue crack growth resistance of material in the axle body is notably higher (the fatigue crack rates are lower) than of the material in the axle bolster and this seems to be in contradiction with the results of the performed fatigue tests. However, each fatigue degradation process consists of two main stages and that is the fatigue crack initiation and the fatigue crack propagation. In smooth specimens, the fatigue crack initiation represents more than $90 \%$ of the total number of cycles to fracture. Presence of a notch on the surface significantly changes the ratio between number of cycles required for crack initiation and propagation ratio and this is the case of the fatigue crack growth tests where an artificial notch is used for acceleration and localisation of the fatigue crack initiation. According to authors of [2, 3, 14-21], materials with lower strength create on the crack tip a plastically deformed zone which slows down the fatigue crack propagation. In case of materials with higher strength this zone is not so significant and less influences (slows down) the fatigue crack propagation. The material in the axle bolster had a significantly higher resistance to fatigue crack initiation than the one in axle body, but when a crack was initiated from the artificial notch, the material in the axle body had higher resistance to the fatigue crack propagation due to creation of this plastically deformed layer.

\section{Conclusions}

Tensile tests, ultrasonic fatigue tests and fatigue crack growth tests were carried out on specimens manufactured from two parts (axle bolster and axle body) of a C30 steel railway axle. Based on obtained results from these tests the following can be concluded: $\square$ difference in mechanical properties (UTS, yield point, elongation, E) between specimens machined from axle bolster and axle body is negligible,

$\square$ specimens manufactured from the axle bolster show a significantly higher fatigue strength than the ones manufactured from the axle body,

$\square \quad$ the difference in fatigue limit evaluated for $\mathrm{N}=2 \times 10^{8}$ cycles between the axle bolster and axle body material is $\Delta \sigma_{\mathrm{a}}=56 \mathrm{MPa}$,

$\square$ specimens machined from the axle body show higher resistance against fatigue crack growth when compared to the specimens from axle bolster,

$\square$ different deformation levels of various parts of just one component created during the manufacturing processes resulted in significantly different fatigue properties, namely of fatigue strength and fatigue crack growth rate.

\section{Acknowledgement}

The research was supported by the European regional development fund and Slovak state budget by the project "Research centre of University of Zilina", ITMS 26220220183 ( $90 \%$ ) and by project of bilateral cooperation APVV no. SK-CZ2013-0047 (10\%).

\section{References}

[1] GUAGLIANO, M., TRSKO, L., BOKUVKA, O., NOVY, F.: Mater. Eng. - Mater. Inz. 2012, vol. 19, No. 3, p. 117-123.

[2] BOKUVKA, O., Nicoletto, G., GUAGliano, M., KUNZ, L., PALCEK, P., NOVY, F., CHALUPOVA, M.: Fatigue of Materials at Low and High Frequency Loading (in Slovak), Zilina: EDIS, 2014.

[3] PAlCEK, P., CHALUPOVA, M., NICOLETTO, G., BOKUVKA, O.: Prediction of Machine Element Durability, $1^{\text {st }}$ ed., Zilina: EDIS 2003.

[4] BURDACK, M.: Eng. Fract. Mech. 78(5), 2011, p. 742-753.

[5] PETRAK, G.: J. Eng. Fract. Mech., 6, 1974, p. 725.

[6] ROMANIV, O. N.: Proc. Basic Mechanisms in Fatigue of Metals, ACADEMIA Praha, 1988

[7] FURBACHER, I., MACEK, K., STEIDL, J.: Catalogue of Technical Materials (in Czech), 1 ${ }^{\text {st }}$ ed., Prague : Verlag Dashofer, 2004.

[8] SKOCOVSKY, P., BOKUVKA, O., KONECNA, R., TILlOVA, E.: Material Science for Mechanical Engineers (in Slovak), $2^{\text {nd }}$ ed., Zilina : EDIS, 2006.

[9] TRSKO, L., BOKUVKA, O., NOVY, F., HADZIMA, B.: Mater. Eng. - Mater. Inz. 21 (3), 2014 pp. 104-108

[10] PUSKAR, A.: High Frequency Fatigue of Materials (in Slovak), 1 15t ed., Zilina : EDIS, 2014. 


\section{COMMNICOIIONS}

[11] PUSKAR, A., BOKUVKA, O., PALCEK, P., MESKO, J.: Machinery (in Slovak), 9, 1987.

[12] KITAGAWA, O.: Int. Conf. Stockholm, Sweden, EMAS, 1982, p. 1051.

[13] BOKUVKA, O., PUSKAR, A., NICOLETTO, G.: In Proc. of $8^{\text {th }}$ DAS, Godollo, 1991, p. 36.

[14] RITCHIE, R. D.: Application of Fract. Mech. to Fatigue Crack Propagation, Univ. California, 1981

[15] BURSAK, M., BOKUVKA, O.: Communications - Scientific Letters of the University of Zilina, vol. 8, No. 4, 2006, pp. 34-37.

[16] LUKAS, P., KLESNIL, M.: Machinery (in Czech), 1, 1978, p. 36.

[17] NOVY, F., BOKUVKA, O., TRSKO, L., CHALUPOVA, M.: Annals of Faculty Engineering Hunedoara, Int. J. Eng. X, 2, 2012 , p. 231.

[18] BOKUVKA, O., NICOLETTO, G., PALCEK, P.: Proc. of Materials Development in Rail, Tire, Wing, Hull Transportation, AIM : Genova, 1992, p. 1.123.

[19] BURSAK, M., BOKUVKA, O.: Communications - Scientific Letters of the University of Zilina, vol. 11, No.1, 2009, pp. 27-30.

[20] ZERBST, U., KLINGER, C., KLINGBEIL, D.: Eng. Fail. Anal., 35(15), 2013, pp. 54-65.

[21] OGNJANOVIC, M., SIMONOVIC, A., RISTIVOJEVIC, M., LAZOVIC, T.: Eng. Fail. Anal., 17(7-8), 2010, pp. 1560-1571. 